\title{
Risk assessment of groundwater pollution with a new methodological framework: application of Dempster-Shafer theory and GIS
}

\begin{abstract}
Managing natural groundwater resources is challenged by nitrate pollution resulting from agricultural activities. This issue is emerging as an important environmental concern that needs to be addressed through effective groundwater management. Groundwater assessment is an important aspect of groundwater management, particularly in arid and semi-arid regions. This study focused on the Kerman Plain, which is exposed to intensive agricultural activities and land exploitation that result in intense land pollution. The effects of nitrate pollution may be controlled by applying specific measures. Dempster-Shafer theory (DST) was applied in this study to develop a new methodology for assessing pollution risk. Applying this theory as a pioneering approach to assessing groundwater pollution risk is the novel component of this research. This approach provides a major advantage by dealing with varying levels of precision related to information. The spatial association between DRASTIC parameters including $\mathrm{D}$ (depth of water), $\mathrm{R}$ (net recharge), A (aquifer media), $\mathrm{S}$ (soil media), $\mathrm{T}$ (topography), I (impact of vadose zone) and C (hydraulic conductivity) and underground nitrate occurrence was evaluated by applying bivariate DST to assign mass functions. Dempster's rule of combination using GIS was then applied to determine a series of combined mass functions for multiple hydrogeological data layers. The uncertainty of system responses was directly addressed by the proposed methodology. Finally, the modified DRASTIC map with the highest validity and accuracy was selected and combined with the damage map. The comparison between nitrate distribution and vulnerability and the risk maps exhibit high similarity between different vulnerability degrees and nitrate concentrations. Long-term planning of preventive measures and associated developments can be aided by the regions with low and very low risks located in the northeast, northwest, and central regions.
\end{abstract}

Keyword: Dempster-Shafer theory; GIS; Nitrate; Risk assessment; Hydrogeological parameters 